\title{
Perspectives: A dialogue upon the question of value in film education
}

\author{
Alan Bernstein* - Independent researcher \\ Andrew Burn ${ }^{\dagger}$ - University College London, UK
}

\begin{abstract}
The question of aesthetic value remains a source of tension within diverse film education environments. While film-makers and audiences have visceral experiences of the value of cinema, these experiences are troubled by a contemporary film studies that tends to adopt a more relativist approach, suggesting that the experience of value is reflective of sociocultural subjectivity. Speaking from two different perspectives, Alan Bernstein and Andrew Burn explore the role of value in film education, and film culture more widely, in 2019. While Bernstein argues for a reinstatement of value as a fundamental aspect of how film is experienced and understood in educational contexts and beyond, Burn contextualizes questions of value within a wider framework of semiotic and aesthetic theory, arguing for a multimodal approach that takes into account the multifaceted nature of film.
\end{abstract}

Keywords: theory/practice debate; aesthetic value; taste; Bourdieu; aesthetics; semiotics

\section{THE VALUE OF VALUE, by Alan Bernstein}

The history of film as a subject to be thought and written about, particularly in universities or training institutions, has been characterized by a 'great gulf fixed' between theory and practice. André Bazin was close to being the last theorist who had a significant impact on practice. Well-known examples of this impact include how Bazin's thought about the significance of the camera - the photographed scene, and the consequent rejection of montage, is the origin of the long, curious history of the fetishism of the long shot, still much with us. An even more subtle and important effect of Bazin's thought arose from the refocusing of attention away from elements such as montage and narrative, to look for primary aesthetic value in the scene itself, empowering the preserve of the director - theory that had an immense impact via the development of directorial aesthetics.

Since then, the gap between film practice and theory has widened, to the detriment of theory certainly, and perhaps practice as well. Surveying the history of film schools and practical conservatoires in the UK, Duncan Petrie described how:

the subsequent professionalization of film within the academy from the 1970s onwards coincided with a new interest in the wider social, psychological and political significance of the moving image, which was pursued through an engagement with the theoretical discourses of semiotics, psychoanalysis and Marxism. While this may have energized intellectual film culture, it moved the focus away from the central concerns 
of many practitioners - particularly those operating outside the realm of avant-garde and political film-making. (Petrie and Stoneman, 2014: 6)

One of Petrie's interviewees goes on to note how:

The practitioners pour scorn on the scholars and hold their analyses to be incomprehensible irrelevances. The academy barely tolerates practitioners and thinks their more abstract musings are inadequate inanities. Students, 'great artists' in the making - are in the middle. (ibid.: 7)

I have been in a position to have to think through this problem on a day-to-day basis, teaching some form of articulated reflective practice in an obsessively practical course as the Head of Studies for 12 years at the London Film School, and many teaching years before. At the London Film School, I took my role to include an awareness of theory set alongside a thorough knowledge of the history of practice, and a constant process of looking for relevant connections between the two. Film-making inside a film school, mirroring the professional world, presents itself as a process that throws up a series of problems requiring solutions. Teaching anything in a film school, from cinematography to screenwriting, involves helping students shape these problems for themselves and resolve them in their individual practice.

In my opinion, the central issue that separates theory and practice in film education is the issue of value. The conceptual structure that organizes students' own sense of their practice, and that is constantly foregrounded in the teaching of practical film-making, is that of aesthetic value, in the form of questions of failure and success, good and better. Much academic writing is deeply suspicious of the concept of value, treating it as ideology, or as an expression of an ephemeral feeling ('taste'). Recent discussions of value have focused on monolithic conceptions of value that are seen to exclude many categories of voice, by class, race or gender. Value and connected structures, such as canons and 'authorities', consequently come to be treated with great scepticism.

As a result, in a practical context, critical studies premised on these views often orients itself to opposing the students', and their teachers', conception and experience of value. In practical teaching, there is a constant, and often critical, discussion with students about values, about what is good, or better, what is failure or success. But, in the face of arguments that the conception of value itself is meaningless or pernicious, students feel they know better and turn away, while teachers uneasily offer that 'of course it's all taste or ideology, but perhaps, after all, this way of doing it is better'. The outcome risks being that engagement with theory is simply discredited.

Students are sustained in their view of value by two very large facts. The first is that the way in which film audiences organize their thought about films is fundamentally value based. Audiences believe films are better or worse, and think in terms of failure and success. Second, and even more damaging to the possibility of relations with theory, students know that taking these kinds of value judgements seriously is absolutely central to the many processes of professional film-making practice.

Looking at the ways that practitioners and audiences work with value, I think there is a way to use a conception of value drawn from philosophical aesthetics that can be relatively stable, but not exclude change over time, and that can avoid being monolithic or socially exclusive on the one hand, or private on the other. A conception of this sort, to whatever extent it seemed to apply, presented here in perhaps the way a film-maker would call an outline, might make it more comfortable once again for academics and students to sit in the same screening room. 


\section{Film-makers}

People who make films constantly use value terms. They want the films they make to be good, and have ideas about what would make them good. The cinematographer consults with the director about the detail of the shot, or vice versa. Both are committed to making the film good. Making it good at this point may involve something drawn from the possibilities of the script, or personal experience, or certain external commitments. It may be something that can be categorized in aesthetic terms such as 'exciting', 'moving', 'real', 'funny', 'frightening' and 'sickening'. At other times, it may just be described in intuitive terms: 'try it this way', 'that way doesn't feel right' - expressions perhaps of their professional histories of success or failure. Every person on the crew organizes his or her work in accordance with interpretations of value: every activity can be carried out in recognizably better or worse ways.

A central element of the evaluation of the work is the imagined experience of the audience. Film-makers refer constantly to monitors or sound systems that replicate ways an audience would experience the developing film under the best conditions. Decisions are checked by practitioners looking at their work or listening to it from the precise physical point of view of an audience. The film process consists of a vast number of elements created, and then checked and revised, by members of the crew. They transform themselves momentarily and repeatedly into an imagined audience, to test whether the work is good enough. To recall Richard Wollheim (1998: 43), 'an artist must fulfil the role of agent ... but he must also fulfil the role of spectator'.

Practitioners review their work by imagining different audiences. Cinematographers and sound designers may imagine an audience of other specialists like themselves. Some directors may imagine an audience of a very few talented viewers who seem to share sensibilities with the directors themselves, or an audience with elements of a common identity. Directors may try to imagine more than one audience in order to compromise successfully between them.

This tells us that what practitioners look for as value is the ability of a film to give a defined audience a rich experience: complex, satisfying, fun, exciting, shocking, stimulating. Film-makers expect that the outcome of their work - the film - can succeed or fail in giving them such an experience.

\section{Audiences}

For audiences, films are primarily an experience. The experience of the film is nested in structures of value judgements. Audiences must choose which film they are going to see, and they do this in a context of value advice and inducement via personal conversations, social media, advertising blandishment, educational recommendation, serious reviews and so on, all suggesting that one film is more important than another.

Film viewing is characteristically social, so discussions of film experience take up a share of ordinary conversation, and they largely take a value-oriented direction: 'Did you like the film?', 'Yes, but ...'; 'Have you seen such and such? I thought it was great'. The experience of a film in itself exerts pressure towards value discussion. The experience can be intense, and that generates the desire to reflect, resist or celebrate, examine moments of delight or disgust.

The film experience is very complex. As an artefact, any film is made of details rendered by many skilled technicians working over a long period. The audience brings to it their own complexity of film knowledge, social knowledge and individual histories. The sheer complexity makes value comparison part of the experience, because to 
be articulated there has to be compression, and a central form of compression is by reference to other film experiences using value comparison.

\section{Value}

The way that values circle around the film experience for both practitioners and audiences leads to a general form of film value: value in film is the capacity of the film to deliver a rich and satisfying experience for a viewer. (I have drawn a great deal here on Chapter 1 of Budd, 1995.) This is a very inclusive definition. Any viewer can contribute to an identification of value. If they are struck by a film or an element of a film, they can turn to talk to a friend. If they say 'That was the best horror this year', that is evidence for the value of the film, for its capacity to deliver an experience of value. As with evidence in many areas, it may be challenged by other evidence. Their friend says, 'But the last part kept saying the same thing over and over'. Either viewer can go back in memory into the complex experience to find reasons for their disagreement: details of the scenes that struck them, or details of performance; perhaps the psychology or ethics of an action; an account of a certain element of the narrative, thoughts the film seemed to have, or how it showed the world. Or they could talk about the morality of a scene or the presentation of a character.

This discussion is a discussion about value if it is responsive to reasons arising from the experience of the film. 'It's just not my kind of thing' or 'Because she reminded me of my mother' would not count. The discussion must be striving towards intersubjectivity. This in no way excludes emotions, which are central to these discussions; if the claim is that the emotions are generated by the film, then it can be a comment on its value.

The discussion is like other reason-based discussions: people give different reasons; the reasons weigh more or weigh less. The process of recognizing and articulating value may be more easy or more difficult. Different capabilities in audiences can make recognizing different values easier or harder. The more a viewer knows about cinema, the more sensitive they are to the film's use of convention for effect, successfully or not. But perhaps those viewers are less attentive to the force of innovation.

The more attentive a viewer is, the better they may be at recognizing value and reasoning for it. Some people may be more attentive to their own feelings than others. Commitment to the film creates a higher quality of attention, and makes it easier to see values. Particular commitments or identities have this effect, of a higher quality of attention. So, a viewer from a certain community may be more sensitive to values, watching a film describing elements of this community. (There is an asymmetry here: because commitment makes it easier to find the reasons why a film is good or better, positive judgements are more reliable than negative judgements.)

Discussion can lead to an agreement on value, but there is no loss when there is no definitive conclusion. This just reflects the difficulty of identifying value in the film. Even with no agreement, the discussion can be fruitful, revealing new values.

A value conclusion, however, is a discovery about the film. Of course, like any other discovery, it is likely to be developed or superseded over time. The director imagines an audience and works to create value in the film, conscious of a specific audience. But the value might be available to very different audiences. It seems possible that Douglas Sirk was imagining an audience that included the later sensibilities of Rainer Werner Fassbinder. But he would not have had to, in order to have created the images of women's lives with the richness and pain that Fassbinder recognized as so valuable. 


\section{Critics}

There are wide social conversations about film value, across space and time. As ever, critics read other critics and then write reviews. They too can recognize value and argue about it. Characteristically they use a language of value: 'better' and 'worse'. Social media has expanded the range of discussion immensely. As the discussions spread across audiences, they spread across cinema, so the value of films that appear very quietly can be recognized in larger and larger communities. Individual films (and via those films, their directors) have revealed more value over time, and conversely other films seem to have less value now than they were thought to have in the past. We could trace how the discovery of value in Hitchcock's films, and perhaps particularly in Vertigo (1958), has developed as writers have recognized more complex values than just the mastery of suspense. Perhaps Bergman's Persona (1966) is an example of a film where the values that viewers once described seem less secure than they did.

Characteristic of this system is that it rewards bringing hidden film value to light, giving people reasons to see earlier films they might otherwise not have seen, giving them experiences they value. Bazin's reassessments of, say, Murnau, Stroheim, and even Renoir, were very important in this way (see Andrew, 2013: 213 and on). The value discussion draws the attention of practitioners, film-makers and film students to important elements in films that they can use for experiment and incorporate in their own work. In this respect, the sense of value can be both motive and reward for a process of discovery and rediscovery. The history of the long take, for example, is a history of value, in how the impact of a formal device has become the subject of discussion beyond film-makers and for a wider sphere. The nouvelle vague constantly drew on their own recognitions of value in Italian and American cinema to construct their innovations, from absorbing their own defences of Viaggio in Italia (1954), to Godard recognizing the relation between his own cinema of authenticity and that of Minnelli, in the scene in Le Mépris (1963) when Michel Piccoli describes his gesture as 'comme Dean Martin dans Some Came Running'.

\section{Canons and authorities}

If someone asks a person who knows, 'what is neo-realism?', the proper answer will include a list of films. That list is already there, ready to be used; it is a canon, a list of films that demonstrates a particular set of conclusions about value at a particular time, for a particular range of audiences. If it succeeds in this, it is the result of discussions of the values of many items. Some of these discussions have clear outcomes; if they do not, the canon can reflect that. (The Gospels, for example, the original canon in Christian culture, retain significant differences in their narratives.)

A canon becomes constrictive when it fails to respond to works that have reasons to be there, or when the reasons for a film to be there no longer convince, but the film remains. The canon can then be replaced by a new canon, and then the older canon is evidence of history and a measure of change. The discussion of alternative canons is a record of the development of an art, but it is also a means by which the art itself develops, as practitioners look back for impetus.

Most canons are dynamic, responding more or less quickly to the effect of discussions of value in their area. They are a way of both preserving old thoughts and making available new thoughts, a moving measure of achievements, the mode of transmission of the history of cinema. Canons have always been fundamental in the training of artists. No one can take account of the whole body of an art in their 
development, so canons allow new artists to work from, or even against, the best of their art.

Authorities share some things with canons. There will always be authorities in any given art. The authority is the person who has seen the film before you, who draws your attention to it, who thinks it is good, who gives you reasons for seeing it and seeing value in it. Authorities bring the past to the discussion and create connections. Alain Bergala (2016: 4) speaks of a passeur, a ferryman. If someone has seen a lot of films or written about them well, you can use them as an authority, meaning simply that you take their views seriously about where to look for value. If you do not see the values, it does not necessarily mean that they are not there, nor that they are there and you have failed to see them. It means that the authority was of no use to you in that instance.

Authorities, like canons, lose their authority in the world of values more or less quickly if they are not listening or not joining the discussions. Unlike canons, they do not become history, although they may become historians and stay useful in another way. Andrew Sarris's (1985) obsessive hierarchies may be an example: their authority is hard to accept now, but they record part of the important history of the revaluation of the American cinema.

\section{Conclusion}

It is possible, as we know, to teach or research film and avoid the issue of value. After a while, though, I believe it is just missing the point. If, in film thought, the pattern of decisions of film-makers is of importance for understanding or describing films properly, then discussions of film must come to terms with the centrality of value. The same applies for acknowledging, and perhaps examining, the rich or otherwise experiences of audiences. In practical courses of film education, in the classroom, studio or cutting room, value will be constantly present, explicitly or implicitly. If students must wait for the teacher to leave the room to compare, argue, resolve and exercise values as their guide to practical choices, what does that say for the teaching?

The task of fending off value, of pulling back to value-free theory, is difficult and confusing. My view is that it is unnecessary. There is an effective, useful way for film theory to return to the kind of place Bazin, for example, inhabited, recognizing and engaging with value as the robust, independent presence it is in film culture, thereby reopening the vital dialogue with practitioners.

\section{CULTURAL VALUE AND THE SEMIOTICS OF THE MOVING IMAGE, by Andrew Burn}

The question of value in film, as in the arts more generally, is of critical importance for many of the reasons Alan Bernstein adduces in 'The value of value'. From my perspective, it is true that cultural value and the category of the aesthetic have become very confused areas in teaching, practice and theory. In this respect, the picture Bernstein paints of film teachers avoiding the question wherever possible is entirely plausible. It may also be true that the theoretical discourses on which Bernstein lays the blame - 'semiotics, psychoanalysis and Marxism' - have contributed to the confusion to some degree. Nevertheless, it is this bundle of theory that I would like to unpick a little here as, in my view, theory can offer at least some of the answers.

To begin with, these theoretical movements need to be disentangled. My principle counter in response to 'The value of value' is that some form of semiotics is indispensable to an understanding of how value is claimed and negotiated by 
film-makers, critics, audiences and film educators. Before I embark on this, however, I would like to comment briefly on the other two categories.

In relation to Marxism, it may well be the case that reductive, sternly circumscribed ideological critiques of films are of limited use to film-makers, audiences, teachers or students. My sense is, however, that the days of such reductive readings are long past, and that contemporary neo-Marxist readings are likely to be considerably more nuanced. In my own work, however, I am constantly reminded of the importance of the work of one of the greatest practitioner-theorists in the history of film, Sergei Eisenstein (1968). Not only are Eisenstein's ideas informed by a sense of the politics of film narrative, but his extension of montage theory to accommodate the coordinated rhythmic patterns of action, music, filming and editing anticipate many of the arguments I wish to advance later in this article about the value of a multimodal approach to film. In a general sense, then, I would argue that the politics of representation are indissolubly related to the aesthetics of film form.

In relation to psychoanalysis, my own experience has been that semiotics offers more helpful interpretations of film, demonstrable through systematic analysis, than the speculations of psychoanalytic theory. However, I would make some exceptions, especially in the case of horror, whose peculiar invocations of profound fears in childhood and adulthood are difficult to explain, and - speculation notwithstanding - can sometimes be most convincingly described, at least, through the apparatus of psychoanalytic theory. A telling example here is Carol Clover's Men, Women and Chainsaws (1993), with its influential theories of the 'final girl', and of victim-identified audiences.

So, why is semiotics still useful? Taking a well-known example, the semiotics of Christian Metz (1974), which produced the notorious 'grande syntagmatique', can of course be critiqued for its limitations. Metz's work raised important questions, however, which still demand to be addressed by critics, theorists and practitioners, three of the constituencies that Bernstein invokes. Metz argued, for example, that there can be no proper grammar of the moving image below the level of the shot, proceeding to elaborate his own categorization of shot types and their 'grammatical' characteristics. In my own work, while I dispute his assertion (Burn and Parker, 2003), I find this perspective valuable in one general respect - that it imagines a 'grammar' of film. While grammar, as a linguistic term, is in some respects limiting, it does allow in principle for a systematic, descriptive account of the formal properties of film texts. Even those who eschew semiotics find it impossible to do without some kind of system of this kind. Indeed, the aesthetics of the long shot, which Bernstein employs as an instance in the history of value, is a quasi-grammatical term. It would be impossible to discuss the long take without a consideration of the changes in camera movement, angle, focus and distance that in certain ways perform the function of cuts, or the sequences of sound that accompany them, as in Walter Murch's account of the restoration of Orson Welles's Touch of Evil (1958), and in particular the sound montage of the long take that opens it (Axmaker, 2008). These formal structures are a kind of grammar, performing the functions of verbs, adjectives, systems of person and so forth in language. Whether they are developed explicitly as a grammar, as in Kress and van Leeuwen's Reading Images (1996), or left relatively informal, they operate as a form of semiotics, and in this respect follow logically from Metz's argument that film operates in some respects like a language. We might add that, where film does not operate like a language, the analogy of language can still help us develop distinctive analytical terms and frameworks. To take one example, I would dispute Metz's argument there can be no proper grammar of film below the level of the shot, and argue that the level 
of the frame has its own distinctive grammar of spatial relations, readily apparent in related forms that function through the selection of frames, such as storyboarding, publicity stills and even the process of setting up a shot.

What is at issue here is not whether film has a kind of grammar. Rather, it is what descriptive apparatus is best for the job at hand, and at what level of technical detail. It may be that a film-maker does not need to venture too far into the detail of the process of focalization employed by Genette (1980) to describe more accurately the phenomena often referred to in popular discourse as point-of-view or perspective in literature, and applied subsequently by Chatman (1980) to film. It may also be the case that a group of 13 year olds studying film in school do not need too much detail here, although for different reasons. Perhaps, again, an analogy with language might help. A novelist may never need to grapple with the finer points of the theory of taxis in grammar, or an actor with Halliday's theory of tone and tonicity in spoken language. Yet the lack of practical need does not subvert the validity of the theory, nor the likely value of its contribution at some level to better general understanding, not least in schools and colleges, of how human beings communicate.

\section{Aesthetics and value}

So far, it may seem that the discussion of semiotics and systems of signification has drifted away from the question of value. From my perspective, however, they are intimately related, and before proposing exactly how, it is necessary to unpick the question of value a little. In the Western philosophical tradition, at least, three approaches to the question of aesthetic value can be derived from the work of Aristotle: (1) the notion of the aesthetic as the formal properties of art (in this case, principally drama and music) and the emotional charge it produces; (2) as sense perception; and (3) as the shaping of rhetorical discourse to move and persuade. By the time of Kant's (1952) aesthetic theory, as formulated in the Critique of Judgement in 1790, the first of these had become most prominent, developed as an explanation of how art - but also nature - inspires experiences of the beautiful and the sublime. As is well known, Kant's (1952) notion of a 'pure gaze' capable of recognizing these qualities was critiqued by Bourdieu (1984) in the twentieth century, in what is effectively a reversal of Kant's model. Bourdieu (ibid.) argued that cultural value is not a timeless quality of the artobject to be recognized by a cultural elite, but rather a product of social class and education. It seems that it is the instability and doubt in the field of aesthetics that follows from Bourdieu's argument that Bernstein notes ruefully in 'The value of value', noting current academic approaches to value as 'an expression of an ephemeral feeling ("taste")'. Indeed, uncertainty among teachers and students is to be expected following a general destabilizing of what were once believed to be generally agreed certainties.

However, it seems to be the ephemerality, instability, and perhaps relativity, implied through the idea of taste that Bernstein rejects in favour of something more sustainable, more founded in collective judgement and debate, and more related to qualities of the cinematic artworks in question. I believe that there may be sources of reassurance. While it is certainly true that Bourdieu's critique of Kant asserted the role of taste and its relation to social class, that is not to say that there is no value, no judgement of value, no discussion or debate. Rather, it is to assert that these things are constantly important - but that they are socially negotiated. Bernstein recognizes this, describing how value is differently judged by artists, critics and audiences, and 
by people with different experiences of film. He also emphasizes the importance of history: how the evaluation of individual films and directors is subject to revision over time. On these two features of the apprehension of value we surely agree: that it is constructed through debate and that it evolves over time.

We also agree in some respects about the question of canons. The perennial debate about value, of course, produces marked hierarchies of valuation in which some films, directors and narratives are judged to be more valuable than others. This is the process that Raymond Williams (1961) termed 'the selective tradition' in his incisive analysis of how culture is produced. The role of 'authority' may be where Bernstein and I differ somewhat, however. The function of the selective tradition is to judge some cultural objects more valuable, worthy of attention and deserving of preservation than others. However, from Williams's point of view (and my own), the interesting question here is who gets to do the selection? This is not necessarily a sinister process - but the sifting out, sorting, ranking and whittling down that happens in the aggregated commentariat over the decades and centuries certainly privilege some voices above others. These may well be the voices of well-informed, expert opinion. They may equally be the voices of men rather than women, or white rather than diverse commentary (both distortions that we have seen in the recent casting practices and their associated debates in Hollywood). The point is that the process of selective valuation over time is something that itself is worthy of analysis, judgement and comment by our students and by us, their teachers. We do not need to teach inflexible canons - and, indeed, Bernstein suggests this himself. We just need to explore with students how such canons come to be, who constructs them and in whose interest.

Returning briefly to Aristotle, it is notable that two of the aspects of his philosophy that I observed - sense perception and rhetoric - have become separated out in contemporary thought from questions of artistic form. While neither of these are addressed by Bernstein, I would like to propose in passing that they both belong to the general discussion of aesthetics and value. The sensory domain, although discussed by Kant, seems largely evacuated by the remoteness of his vision of the aesthetic experience, as Bourdieu (1984) remarked. Bourdieu himself makes an effort to reinstate it in relation to popular culture, describing the visceral, sensual, carnivalesque nature of the popular aesthetic. Bernstein does not explicitly say so, but I wonder if his choice of examples, drawn largely from the history of European art-house cinema, implies that value is largely to be found here? If so, we must differ here too. Alongside the work of the directors he cites - Hitchcock, Murnau, Stroheim, Renoir, Godard - may we not also place directors whose work troubles conventional distinctions of art-house and commercial cinema - Ang Lee, Steve McQueen, Kathryn Bigelow, Baz Luhrmann - and those who make powerful narratives in an unashamedly popular style - James Cameron, Steven Spielberg, Peter Jackson? Certainly, the sensory domain - and the affective, as Bernstein argues - must play a large part in any account of the aesthetic strategies at work in the films of these directors.

\section{Multimodality and film}

My central aim here is to gather together these disparate aspects of the value debate within the realm of semiotics. In doing so, I locate my argument not in the semiotics of Metz or his successors, but in the relatively recent field of social semiotics and its related domain of multimodality (Kress and van Leeuwen, 2001). Briefly, these approaches propose that the processes of signification can only be properly understood within 
the social contexts in which they occur, and that they are shaped by the interests of the sign-makers who create and exchange them. For the purposes of this debate, the signs and sign-makers in question may be the film-makers and their films (all shaped by particular social contexts, and by changing successive contexts), or they may be the critics, students, teachers and audiences who Bernstein describes (again transforming the films, interpreting them, unstitching them, perhaps even, today, remixing them, in particular social contexts). This is an image of dialogic change - of signs and meanings shifting over time, sometimes gradually and sometimes violently, sometimes preserving long-standing beliefs and values, and sometimes challenging them. It is a process that seems to me very like the kinds of debate and discussion for which Bernstein seems to hope.

Meanwhile, multimodality proposes that the splintering of semiotics into specialist forms to address different modes of communication - language, gesture, writing, music, visual design and so on - fails to do justice to the multimodal nature of the world and its cultural forms. Film is the ideal example. While traditional film semiotics has attended largely to the processes of filming and editing (Metz (1974) is the perfect example), the moving image combines the signifying systems of the visual image, dramatic gesture, spoken language, music, architecture, costume design and many others. If filming and editing orchestrate these modes, as I have argued, we still need to attend to how they all function within the larger 'Gesamtkunstwerk' (Burn, 2013).

And so, back to aesthetics and value. I spent some time recently working, with my colleague Gunther Kress, on an analysis of a short film made by a group of 11 year olds (Burn and Kress, 2018). Our concern was to develop an account of aesthetics in relation to multimodality, and our proposal centred on a distinctive conception of the idea of style, which we distinguished from aesthetics. We proposed style as the (multimodal) semiotic toolkit through which the identity, or identities, of the artist is expressed, and aesthetics as the discursive regime in which claims for value are made and negotiated, both by the sign-makers and by their audience. These young filmmakers were making an animation, The Moonstone, ${ }^{1}$ about a young girl and a pair of werewolves, which expressed their particular interests in teenage identity, in the affective charge of the horror genre, and in the possible meanings of werewolves and their transformations. The style of the film was crafted by these young artists to make certain specific claims for value. The film had to measure up to their experiences of werewolf movies (and, indeed, various forms of European folk-tale monsters); it had to create what Noel Carroll (1990) calls the 'art-emotion' of fear; it had to represent gendered roles in certain ways. Success in these respects was what made the film valuable in their eyes, and indeed in the eyes of the adult artists and educators working with them. To realize these claims of value, the style of the film was created in different modes - in the actions of the battling werewolves; in the rendition of the werewolf transformations (see Figure 1); in the voicing of the characters by two of the children; in the music composed and performed by another group of children. Success, validity and value were gained through a coherent deployment of these resources to create a consistent style. 


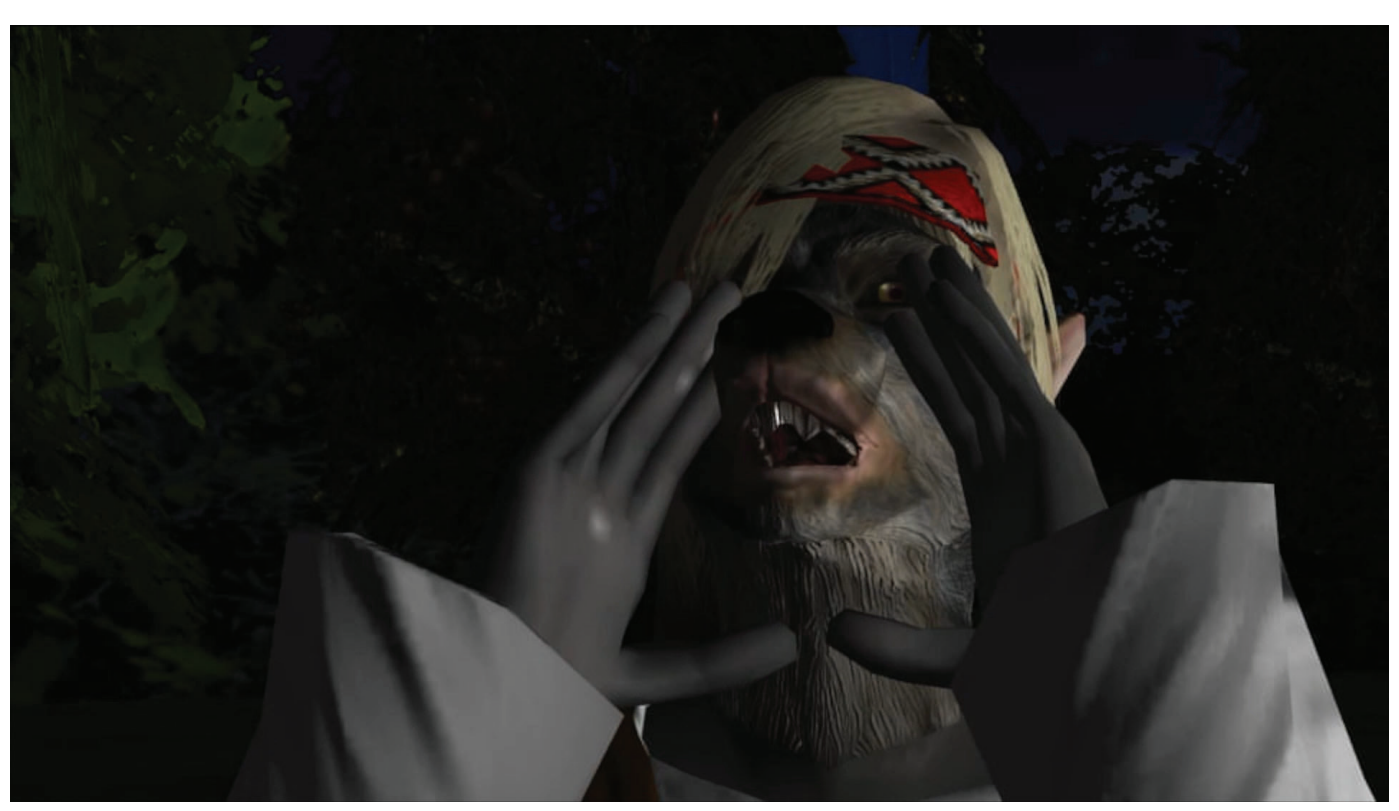

Figure 1: Werewolf transformation in The Moonstone

We further proposed that style is related to genre, and that this is true of all films in some way: they make their claims to value in relation to the system of genre, whether they conserve its patterns or seek to unsettle, transform or even disavow them, a frequent strategy in art-house film. Finally, we proposed that style, as the semiotic toolkit through which aesthetic value is realized, is related to the social semiotic concept of modality, which denotes how a text makes a claim to truth, validity, authenticity and credibility. The critical point here is that a successful truth-claim in this sense (which may be a claim to naturalistic 'realism', or to believable fantasy, or to membership of a settled genre) is intrinsic to the claim to aesthetic value. A film text (or indeed any other text) cannot be valuable unless it is credible. In addition, it is important to observe that while that modality can only be claimed by a text and sign-maker, whether the claim is successful or not depends on the judgement of the audience. It is, therefore, a negotiated property. So the spectators, students and critics in Bernstein's account, debating the values and merits of a film, are not only participating in Raymond Williams's 'selective tradition', but they are also settling the claims to value (including truth-to-genre, 'realism', credibility) made by the film and by its makers.

\section{Conclusion: The social negotiation of value}

As I suggested at the beginning of this article, Bernstein and I agree strongly on one central point: that value is important, misunderstood and often neglected in the educative process (and this is true of primary and secondary schools, as well as film schools). Perhaps I should modify this to say that the discourse of value is ever-present, but reified, implicit and opaque. There is therefore a need to bring such discourses into the light, render them transparent, and subject them to explicit debate.

On the question of semiotics, my argument is not for a return to impenetrable, recondite versions of the semiotics of the 1970s (although we should pay due respect to the thinking of figures such as Metz and Barthes, on whose shoulders we stand). Rather, it is for a more transparent version of semiotics, more generally applicable at different levels. I would have struggled to find a version of Metz, Foucault or Derrida that I could 
have usefully deployed with 13 year olds in discussing film. Multimodality, however, is much more readily adaptable for teachers and students. More generally, my argument has been that, even with those practitioners, critics or theorists who reject semiotics, some form of systematic approach to the processes of signification is indispensable, and, in this sense, we are all semioticians in one way or another. Without the ability to classify formal structures and the social process through which they are made and received, we cannot hope to understand how value is claimed, negotiated, challenged and revised. This was true of Laurence Olivier, struggling to find a way to preserve the unity of Shakespearean text while courting the stylistic repertoires of popular cinema. It is equally true of the 11-year-old werewolf-makers described earlier in this article, who passionately describe their efforts to create convincing werewolves through the grain of the voice, the shape of the animated gestures, the rhythms of the music, and the shot-reverse-shot sequence articulated with it. To end on another note of solidarity with Bernstein's argument, the examples I have used (and always try to use) represent the effort to bring together theory and practice. The theories change and evolve, as do the debates about value, as Bernstein suggests. It would seem that the important thing, however, is the social process of the negotiation of cultural value, the discursive regime of aesthetics and how this can be connected to the art of film-making. It is as true for children as for adults, for teachers as for students, for film-makers as for audiences, and for popular cinema as for art house.

\section{Notes on the contributors}

Alan Bernstein has spent his working career teaching film-making, mostly in the UK. At the London Film School, he was forced by the determination of his students, and the intense commitment of his colleagues, to think unceasingly about the tensions of the visible and invisible in each film, each audience and each of the film-makers.

Andrew Burn is Professor of English, Media and Drama at UCL Institute of Education. His research focuses on media literacy, play, games, film and animation. He previously taught in UK state schools for 24 years.

\section{Note}

1 This film was made as part of the project Montage, Mash-up, Machinima, a collaboration with the BFl-funded First Light, 2012.

\section{Filmography}

Le Mépris (Contempt, FR/IT 1963, Jean-Luc Godard)

Persona (SE 1966, Ingmar Bergman)

Touch of Evil (US 1958, Orson Welles)

Viaggio in Italia (Journey to Italy, IT/FR 1954, Roberto Rossellini)

Vertigo (US 1958, Alfred Hitchcock)

\section{References}

Andrew, D. (2013) André Bazin. Oxford: Oxford University Press.

Axmaker, S. (2008) '"A tremendous piece of filmmaking" - Walter Murch on "Touch of Evil"'.

Parallax View, 7 October. Online. https://tinyurl.com/46obvp (accessed 18 January 2019).

Bergala, A. (2016) The Cinema Hypothesis: Teaching cinema in the classroom and beyond

(FilmmuseumSynemaPublikationen 28). Trans. Whittle, M. Vienna: Austrian Film Museum.

Bernstein, A. (2019) 'The value of value'. Film Education Journal, 2 (1) 71-76. 
Bourdieu, P. (1984) Distinction: A social critique of the judgement of taste. Trans. Nice, R. London: Routledge and Kegan Paul.

Budd, M. (1995) Values of Art: Pictures, poetry and music. London: Allen Lane.

Burn, A. (2013) 'The kineikonic mode: Towards a multimodal approach to moving image media'. In Jewitt, C. (ed.) The Routledge Handbook of Multimodal Analysis. 2nd ed. London: Routledge, 373-84.

Burn, A. and Kress, G. (2018) 'Multimodality, style, and the aesthetic: The case of the digital werewolf'. In Tønnessen, E.S. and Forsgren, F. (eds) Multimodality and Aesthetics. New York: Routledge, 15-36.

Burn, A. and Parker, D. (2003) Analysing Media Texts. London: Continuum.

Carroll, N. (1990) The Philosophy of Horror; or, Paradoxes of the Heart. New York: Routledge.

Chatman, S. (1980) Story and Discourse: Narrative structure in fiction and film. Ithaca, NY: Cornell University Press.

Clover, C.J. (1993) Men, Women and Chainsaws: Gender in the modern horror film. London: British Film Institute.

Eisenstein, S.M. (1968) The Film Sense. Ed. and trans. Leyda, J. London: Faber and Faber.

Genette, G. (1980) Narrative Discourse: An essay in method. Oxford: Blackwell.

Kant, I. (1952) The Critique of Judgement. Trans. Meredith, J.C. Oxford: Clarendon Press.

Kress, G. and van Leeuwen, T. (1996) Reading Images: The grammar of visual design. London: Routledge.

Kress, G. and van Leeuwen, T. (2001) Multimodal Discourse: The modes and media of contemporary communication. London: Arnold.

Metz, C. (1974) Film Language: A semiotics of the cinema. Chicago: University of Chicago Press.

Petrie, D. and Stoneman, R. (2014) Educating Film-Makers: Past, present and future. Bristol: Intellect.

Sarris, A. (1985) The American Cinema: Directors and directions, 1929-1968. Chicago: University of Chicago Press.

Williams, R. (1961) The Long Revolution. London: Chatto and Windus.

Wollheim, R. (1998) Painting as an Art. London: Thames and Hudson. 